\title{
Disc lesions treated with ozone in Pakistan: experience of 23000 cases [abstract]
}

\author{
Umair Rashid Chaudhry, Abdul Hameed, M Farroq, Shahzad Karim \\ Department of Interventional Neuroradiology, Punjab Institute of Neuro Sciences, Lahore - Pakistan
}

\section{ABSTRACT}

\section{OPEN ACCESS}

\section{Citation}

Chaudhry UR. Disc lesions treated with ozone in Pakistan: experience of 23000 cases [abstract]. Proceedings of The World Conference on Ozone Therapy in Medicine, Dentistry and Veterinary. Ancona (Italy). September 22nd - 23rd - 24th , 2017. J Ozone Ther. 2019;3(4):9. doi: 10.7203/ jo3t.3.4.2019.15398

\section{Academic Editor}

Jose Baeza-Noci,

School of Medicine, Valencia

University, SPAIN

\section{Editor}

World Federation of Ozone Therapy, Bolgna, ITALY

\section{Received}

June 17, 2019

\section{Accepted}

December 08, 2019

Published

December 30, 2019

\section{Intellectual Property}

Umair Rashid Chaudhry.

This is an open access article distributed under the terms of the Creative Commons Attribution License (CC BY 4.0), which permits unrestricted use, distribution, and reproduction in any medium, provided the original author and source are credited.

\section{Author Information}

E-Mail: dr_umairch@yahoo.com
Background and Purpose: Direct injection of Oxygen-Ozone in to the discs has proved to be the effective alternative for surgery in patients with disc herniation in many countries around the world. We report our experience with ozonucleolysis with patients effected by lower backache, sciatica and pain cervical region (brachalgia) due to disc herniation including post operative recurrence or disc prolapse.

Material \& Methods: Twenty-Three Thousand patients were treated with single two multiple sessions of Oxygen Ozone therapy. All the patients had CT or MRI evidence of annulus tear/ disc prolapse with clinical signs of nerve root compression. The procedure was performed under angio fluoroscopy using 22/23 G spinal needle without any form of anesthesia. All the patients received intra discal injection of Oxygen Ozone mixture with and without periganglionic infiltration at a ozone concentration $30 \mathrm{mcgr} / \mathrm{mL}$. Among these patients 14000 were males and 9000 were females between the age of $14-80$ years. Therapeutic outcome was assessed 5 months after treatment by using modified MacNab method.

Results: A satisfactory therapeutic outcome was obtained. $55 \%$ of the patients showed complete recovery with resolution of symptoms. $20 \%$ of the patients complained of occasional episodic pain and with no limitation of occupational activity. $15 \%$ of cases showed insufficient improvement. $5 \%$ of cases had insufficient improvement and went for surgery. $10 \%$ of cases never turned up after the first visit.

Conclusion: Intradiscal with and without periganglionic injection of Ozone for herniated discs has revolutionized percutaneous approach to nerve root diseases making it safer, cheaper and easier to repeat than treatments currently use in Pakistan. 